\title{
分散有 $\mathrm{ZnS}: \mathrm{Mn}^{2+}$ 纳米微粒的玻璃 的制备和光学性质*
}

陈一民 刘俊业赵家龙 靳春明 候尚公黄世华 虞家琪 (中国科学院长春物理研究所激发态物理开放研究实验室, 长春 130021)

\author{
向卫东 张军杰 王中才 \\ (中国科学院长春光学精密机械研究所, 长春 130022) \\ 张希清 \\ （复旦大学应用表面物理国家重点实验室, 上海 200433)
}

\section{关镜词纳米材料 捲杂半导体 光学性质}

近年来半导体纳米微粒的光物理性质引起了人们越来越大的研究兴趣. 半导体微晶随着 其尺寸的变小能够表现出光物理性质上的量子尺寸效应 ${ }^{[1-3]}$. 以往人们研究涉及较多的是 半导体微晶的本征特性及其与周围介质的作用. 自从 Bhargava 等 ${ }^{[4]}$ 报道了化学反应合成的 $\mathrm{ZnS}: \mathrm{Mn}^{2+}$ 纳米微粒的光学性质, 掺杂半导体纳米微粒发光性质的研究受到了极大的重视. 掺杂纳米微粒有可能成为新的一类发光材料.

玻璃是分散微晶的良好介质. 分散有半导体微晶的玻璃能够制成光学器件. 对于溶有本 征半导体微晶的玻璃的制备和光学性质研究已经十分广泛. 然而, 关于熔制分散掺杂半导体 微晶的玻璃, 还未见报道. 制备掺杂半导体微晶/玻璃, 对研究掺杂纳米半导体的激发态性质 和发光机理以及杂质相关的非线性光学性质有重要的意义. 众所周知, 半导体中的某些掺杂 离子能够起到发光探针的作用,这些掺杂离子的特征发光常能够给出其周围基质环境的信息. 在半导体微晶中掺杂, 引入发光探针, 能够获得更多有关半导体微晶激发态性质随尺寸变化的 信息. 这可作为研究半导体微晶激发态性质的一种手段. 另一方面, 微晶的限域结构对其中 的掺杂离子的激发态性质以及掺杂离子激发态与半导体微晶本征激发态之间相互作用的过程 也将产生影响.

本文报道掺杂半导体微晶 $\mathrm{ZnS}: \mathrm{Mn}^{2+}$ 玻璃的熔融法制备工作及其在光学性质上的量子尺 寸效应.

\section{1 样品制备}

我们采用熔融法制备 $\mathrm{ZnS}: \mathrm{Mn}^{2+}$ 玻璃样品. 与本征半导体微晶/玻璃相比, 掺杂半导体

1995-12-11 收稿, 1996-02-20 收修改稿

* 国家自然科学基金和中国科学院激发态物理开放研究实验室资助项目 
微晶/玻璃的制备难度在于要在保证半导体微晶在玻璃之中均匀分散的同时要求掺杂离子进 入到半导体微晶之中, 而不是在之外的玻璃中; 要在半导体微晶中形成掺杂离子的光激活中 心. 我们的熔制方案分 3 个主要环节: 1 . 确保 $\mathrm{Mn}$ 进入 $\mathrm{ZnS}$ 晶格; 2 . 确保 $\mathrm{ZnS}$ 微粒在玻璃中均 匀分散形成透明的玻璃; 3 . 热处理得到一定要求的样品. 基玻璃采用钠硼硅玻璃; $\mathrm{Mn}$ 与 $\mathrm{Zn}$ 之比为 $1 \%$; 熔制温度在 $1300^{\circ} \mathrm{C} \sim 1600^{\circ} \mathrm{C}$ 的范围. 通过改变 $\mathrm{ZnS}: \mathrm{Mn}^{2+}$ 与基玻璃的配比和热 处理的温度和时间可控制玻璃样品中 $\mathrm{ZnS}: \mathrm{Mn}^{2+}$ 晶粒的尺寸.

样品 $\mathrm{A}$ 是用上述方法制备的分散有 $\mathrm{ZnS}: \mathrm{Mn}^{2+}$ 纳米微粒的玻璃样品, 其中 $\mathrm{ZnS}: \mathrm{Mn}^{2+}$ 含 量为 $1 \%$ (重量配比), 外观是无色透明的.

样品 $\mathrm{B}$ 中 $\mathrm{ZnS}: \mathrm{Mn}^{2+}$ 的粒径在 $1 \mu \mathrm{m}$ 左右, 是体材料样品.

\section{2 光学性质}

光谱实验是在室温下进行的. 图 1(a)给出了样品 $\mathrm{A}$ 的光致发射光谱, 激发波长 $290 \mathrm{~nm}$. 图 1(b)给出的是样品 $\mathrm{B}$ 的光致发射光谱, 激发波长 $349 \mathrm{~nm}$. 事实上, 不同波长激发下发光峰 值位置没有变化. $\mathrm{ZnS}: \mathrm{Mn}^{2+}$ 体材料样品的黄色发光带归属为 $\mathrm{Mn}^{2+}$ 的 ${ }^{4} \mathrm{~T}_{1} \rightarrow{ }^{6} \mathrm{~A}_{1}$ 发射, 峰值位 于 $580 \mathrm{~nm}$, 半宽度为 $0.2 \mathrm{eV}$. 而分散有 $\mathrm{ZnS}: \mathrm{Mn}^{2+}$ 纳米微粒的玻璃样品 $\mathrm{A}$, 黄色发光带峰值 位于 $591 \mathrm{~nm}$, 半宽度为 $0.65 \mathrm{eV}$. $\mathrm{ZnS}$ 纳米微粒中 $\mathrm{Mn}^{2+}$ 的 ${ }^{4} \mathrm{~T}_{1} \rightarrow{ }^{6} \mathrm{~A}_{1}$ 发射与其体材料中的相 比, 峰值位置变化不大, 略向红移; 而谱带宽度显著增大, 半宽度增大 2 倍. 发光谱带展宽的原 因可能主要有 3 个方面: $1 . \mathrm{ZnS}$ 微晶的尺寸和形状分布, 不同尺寸和形状的微晶中 $\mathrm{Mn}^{2+}$ 与配 位体间的键长有所不同; $2 . \mathrm{Mn}^{2+}$ 在 $\mathrm{ZnS}$ 微晶中的位置不一致, 有的位于中间, 有的靠近表面; 3 . 微晶中电-声子堣合增强.

从图 1 我们看到样品 $\mathrm{A}$ 发光光谱的另一显著特点是, $410 \mathrm{~nm}$ 附近的蓝色发光带很强, 它

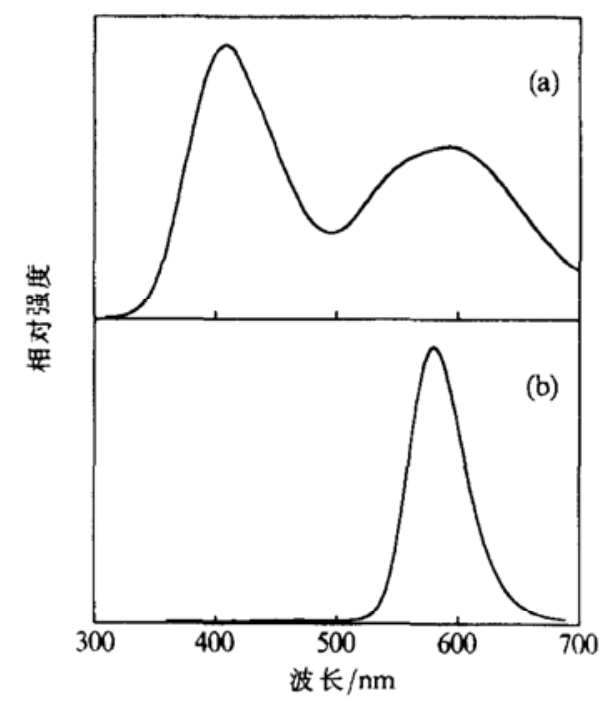

|约 1

(a) 样品 $\mathrm{A}$ 的发光光谱, 激发波长 $290 \mathrm{~nm}$,

(b) 样品 $\mathrm{B}$ 的发光光谱, 激发波长 $349 \mathrm{~nm}$

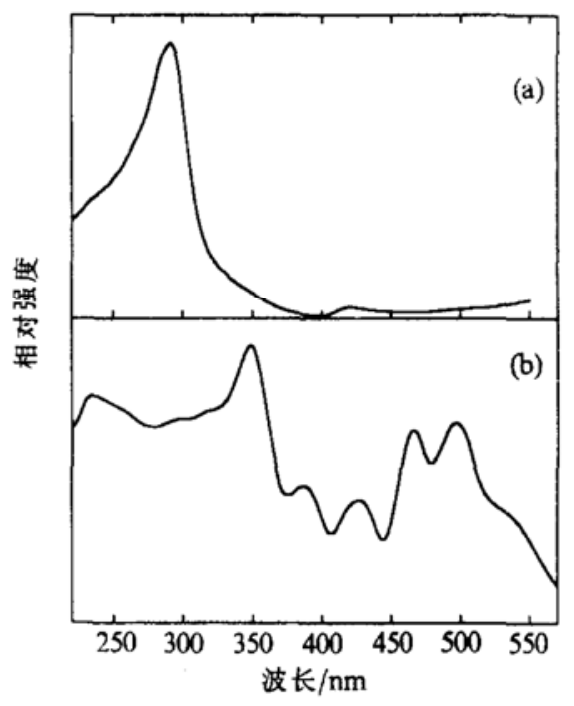

终 2

(a) 样品 A 的 $591 \mathrm{~nm}$ 发光的激发光谱, (b) 样品 B 的 $580 \mathrm{~nm}$ 发光的激发光谱 
属于 $\mathrm{ZnS}$ 的自激活 (SA)发光. 而在体材料样品 B 中 SA 发射很弱, 峰值在 $445 \mathrm{~nm}$ 附近. $\mathrm{ZnS}$ 纳米晶的 SA 发光增强可能是由于纳米晶中 $\mathrm{Zn}$ 空位较多.

图 2(a) 给出了样品 $A$ 的 $591 \mathrm{~nm}$ 发光的激发光谱. 图 2(b) 是样品 $B$ 的 $580 \mathrm{~nm}$ 发光的激 发光谱. 如图 2(b) 所示, $\mathrm{ZnS}: \mathrm{Mn}^{2+}$ 微米粒度样品 $\mathrm{B}$ 的激发光谱有多个激发带. 能量较低的 几个激发带属于 $\mathrm{Mn}^{2+}$ 的 ${ }^{6} \mathrm{~A}_{1} \rightarrow{ }^{4} \mathrm{~T}_{1},{ }^{4} \mathrm{~T}_{2},{ }^{4} \mathrm{~A}_{1}$ 和 ${ }^{4} \mathrm{E}$ 跃迁. 而峰值为 $349 \mathrm{~nm}$ 的激发带属于 $\mathrm{ZnS}$ 的带间跃迁. 从图 2(a) 我们看到 $\mathrm{ZnS}: \mathrm{Mn}^{2+}$ 纳米微粒中属于 $\mathrm{ZnS}$ 的带间跃迁的激发峰已由体 材料的 $349 \mathrm{~nm}$ 移到了 $290 \mathrm{~nm}$. 这标志着带边向高能移动了约 $0.72 \mathrm{eV}$. 根据理论计算 ${ }^{[3]}$, 这 一移动对应 $\mathrm{ZnS}: \mathrm{Mn}^{2+}$ 微晶粒径为 $5.5 \mathrm{~nm}$.

从图 2 我们看到, $\mathrm{ZnS}: \mathrm{Mn}^{2+}$ 纳米微粒 $591 \mathrm{~nm}$ 激发谱中对应 $\mathrm{Mn}^{2+}$ 的几个较低激发态的 激发带弱得几乎观测不到. 其原因可能有 3 个方面, 一是纳米晶中量子限域效应使得与 $\mathrm{ZnS}$ 本征电子-空穴对产生对应的激发更为有效; 二是由于 $\mathrm{Mn}^{2+}$ 的激发态受微粒尺寸效应影响较 大, 有的能级位置有较大改变; 三是纳米晶尺寸宽化和 $\mathrm{Mn}^{2+}$ 位置宽化使得与 $\mathrm{Mn}^{2+}$ 的几个较 低激发态对应的激发带相互重叠.

对样品 A, 我们还做了监测 $410 \mathrm{~nm}$ 的激发光谱, 其激发带与图 2(a) 示出的 $591 \mathrm{~nm}$ 发光 的激发带基本一致. 进一步证实了激发属于 $\mathrm{ZnS}$ 的带间跃迁. 做为参比, 我们还制备了只分 散 $\mathrm{Mn}$ 离子的玻璃样品和只分散 $\mathrm{ZnS}$ 微晶的玻璃样品. 在前者的光谱中即见不到 $590 \mathrm{~nm}$ 附 近的橙色发光也见不到 $410 \mathrm{~nm}$ 附近的蓝色发光. 在后一样品中只能观测到 $410 \mathrm{~nm}$ 附近的 蓝色发光. 这证明, 我们制备的 $\mathrm{ZnS}: \mathrm{Mn}^{2+}$ 微晶玻璃样品中 $\mathrm{Mn}$ 离子确实是在 $\mathrm{ZnS}$ 微晶之中.

综上所述, 我们成功地用熔融法制备了分散在玻璃中的 $\mathrm{ZnS}: \mathrm{Mn}^{2+}$ 纳米晶, 观测到其光学 性质上的显著的量子尺寸效应, $\mathrm{Mn}^{2+}$ 发光的激发谱峰大大蓝移. 由于纳米晶尺寸分布和 $\mathrm{Mn}^{2+}$ 在其中位置分布的光谱宽化效应, $\mathrm{Mn}^{2+}$ 发光带宽度是其体材料中的 3 倍. 纳米晶中, $\mathrm{ZnS}$ 自激活发光显著增强.

掺杂纳米半导体/无机玻璃的制备成功, 对研究掺杂半导体微晶的发光机理和杂质相关的 非线性光学性质有重要意义. 这方面的研究我们将另文报道.

\section{参考文 献}

1 Kayanuma Y, Kuroda K. Quantum size effect of excitonic molecules in $\mathrm{CuCl}$ microcrystals. Appl Phys A, 1991, 53:465

2 Nozik A J, Williams F. Size quantization in small semiconductor particles. J Phys Chem, 1985, 89:397

3 陈一民, 徐叙溶. 半导体微晶电子激发态的量子尺寸效应. 发光学报, 1988,9:85

4 Bhargava R N. Optical properties of manganese-doped nanocrystals of $\mathrm{ZnS}$. Phys Rev Lett, 1994, 72:416 